\title{
O SER MÃE DE CRIANÇA COM DOENÇA CRÔNICA: REALIZANDO CUIDADOS COMPLEXOS
}

\author{
Being mother of child with chronic disease: \\ accomplishing complex cares \\ Ser madre de niño con enfermedad crónica: \\ realizando trabaj os complejos
}

Maria Inez Almeida

leda Harumi Higarashi
Rosemeire Cristina Moretto Molina

Sonia Silva Marcon
Tereza Maria Mageroska Vieira

\begin{abstract}
Resumo
O presente estudo tem por objetivo compreender a experiência de assistência domiciliar prestada por mãe de criança com doença crônica e dependente de cuidados complexos. A pesquisa teve como eixo norteador a abordagem qualitativa. Para a análise e interpretação dos dados, optou-se pela abordagem metodológica do Discurso do Sujeito Coletivo (DSC). Os dados foram coletados nos período de janeiro a março de 2005, por meio de entrevista semi-estruturada com mães residentes em três municípios do Estado do Paraná. Foram informantes seis mães cuidadoras principais da criança dependente de cuidados complexos e que houvesse passado pela experiência de hospitalização nos últimos seis meses. Da realidade dessas mães cuidadoras domiciliares, desvelou-se toda a gama de dificuldades e os meios de enfrentamento encontrados por elas para lidarem com o cotidiano da assistência em seus lares, o que evidenciou a importância do papel educativo-assistencial do profissional enfermeiro para a efetivação desse processo.
\end{abstract}

Palavras-chave: Doença crônica. Enfermagem. Cuidado da criança.

\begin{abstract}
The present study it has for objective to understand the experience of domiciliary assistance given by mother of child with chronic illness and dependent of complex cares. The research had as guide axle the qualitative boarding. For the analysis and interpretation of the data, was opted the methodological approach of the Collective Subject Speech (DSC). The data had been collected in the period between January and March of 2005, by half-structuralized interview with resident mothers of three cities of the State of Paraná. Six mainly mothers that takes care of their dependent children had been informing and that had passed for the experience of hospitalization in the last six months. Of the reality of these mothers, all kinds of difficulties was revealed and the ways of confrontation found by them for deal with the daily of the assistance in their homes, what had evidenced the importance of the educative-assistance role of the professional nurse for the effectuation of this process.
\end{abstract}

\section{Resumen}

El presente estudio tiene por objetivo comprender la experiencia de assistencia domiciliaria prestada por madre de niño con diagnóstico de enfermedad crónica, dependiente de cuidados complejos. La pesquisa se orientó por un enfoque cualitativo. Para el análisis y la interpretación de los datos, se optó por el enfoque metodológico del Discurso del Sujeto Colectivo (DSC). La recolección de los datos se llevó a cabo entre los meses de enero y marzo de 2005, a través de entrevistas semiestructuradas con madres que viven en tres municipios del Estado de Paraná. Las informantes eran seis madres, principales encargadas de los cuidados a niños dependientes de cuidados complejos, que habían pasado por la experiencia de hospitalización en los últimos seis meses. A partir de la realidad de essas madres, responsables por los cuidados en el hogar, quedó en evidencia una gran gama de dificultades, así como las formas encontradas para enfrentarlas en la asistencia a sus enfermos, lo cual demostró la importancia del papel educativo-asistencial del profesional de enfermería, para llevar a cabo ese proceso.
Keywords:

Chronic Disease. Nursing. Child Care.
Palabras clave:

Enfermedad crónica. Enfermería. Cuidado del Niño. 


\section{INTRODUÇÃO}

Os conflitos e dificuldades que permeiam as questões sociais, econômicas, políticas e tecnológicas do país estão representados, em alguma medida, no Sistema Único de Saúde. Tal conjuntura repercute de forma importante na qualidade do atendimento à saúde de um modo geral, incluindo-se neste universo a atenção específica destinada a crianças e adolescentes em nosso país. Assim, garantir atendimento à saúde de forma universal, integral, hierarquizada, descentralizada e com participação popular, assegurando 0 atendimento às necessidades básicas biopsicossocioespirituais, e levando-se em conta a diversidade social, econômica, política e tecnológica em que se insere a grande maioria da população, ainda representa um desafio a ser enfrentado e vencido de forma coletiva.

Diversos estudos na área da saúde infantil apontam o contexto sócioeconômico do país, como fator determinante para a condição de vulnerabilidade dessa clientela frente aos agravos de saúde, pela dificuldade crescente em atender, de forma plena, as necessidades básicas da infância ${ }^{(1-3)}$.

No outro extremo da atenção pediátrica, podemos perceber 0 incremento das ações de alta complexidade. Nessa perspectiva, 0 investimento nas tecnologias voltadas para a assistência hospitalar tem provocado 0 aumento da sobrevida de pacientes graves e com doenças crônicas, o que tem, por sua vez, contribuído para 0 surgimento de outra situação peculiar, que é a alta, numa freqüência cada vez maior, de pacientes de todas as idades com seqüelas e dependentes de cuidados temporários ou permanentes. Contudo, essa nova conjuntura veio expor de forma mais contundente a vulnerabilidade do sistema de saúde e de seus profissionais, nem sempre preparados para dar conta da complexidade do cuidado de forma resolutiva, eficiente e humanizada, tanto no interior dos serviços de assistência à saúde, quanto para assistir adequadamente aqueles pacientes que necessitam da continuidade de cuidados no domicílio(3-5).

Complexa também é a problemática das questões relativas à necessidade de humanização do cuidado à criança e ao adolescente com doenças crônicas, por entendermos que, embora o ambiente físico, aliado aos recursos materiais e tecnológicos, seja de extrema importância, estes não são mais significativos do que a essência humana ${ }^{(6)}$. Desse modo, a humanização, além de envolver 0 cuidado à criança e ao adolescen- te, estende-se a todos aqueles que estão envolvidos no processo de saúde-doença, isto é, a todos os seus cuidadores, em que se destaca a figura e o papel fundamental da família $(3,6)$.

Nos casos de doença crônica, depois de estabelecido seu diagnóstico e prognóstico, normalmente se desencadeia um estado de sofrimento e expectativas diversas na criança e no adolescente, assim como em toda sua família, acarretando profundas transformações em suas vidas, não somente pela doença em si, mas também por suas repercussões sociais, emocionais, afetivas, culturais e espirituais ${ }^{(7)}$.

As fases na história da doença crônica são três: 1) crise, caracterizada pelo período sintomático que se estende até 0 inicio do tratamento; 2) crônica, marcada pela constância, progressão e remissão do quadro de sinais e sintomas; e 3 ) terminal, que envolve, desde 0 momento em que a morte pode ser uma possibilidade, até a sua ocorrência de fato. Todas essas fases são marcantes para a família, já que a doença ocasiona a desestruturação não somente na vida da criança, mas também na vida familiar. Na fase crônica, a família procura desenvolver uma certa autonomia, buscando a reestruturação da vida de seus membros, adaptando rotinas às necessidades impostas pela condição da criança ou adolescente. Configura-se, destse modo, uma nova situação, com o estabelecimento de estratégias para 0 enfrentamento da complexidade e gravidade da doença ${ }^{(8-12)}$.

Diante de um diagnóstico desse tipo, a família tende a se desorganizar num primeiro momento, alterando sua rotina e dinâmica habitual, necessitando lançar mão e buscar as estruturas disponíveis para se reorganizar, satisfazendo suas necessidades e readquirindo 0 equilíbrio ${ }^{(6,8)}$.

Nessa perspectiva, as mães muitas vezes saem do hospital levando nos braços sua criança com necessidades de cuidados complexos, e carregam sobre os ombros novas tarefas, que irão desencadear uma grande mudança de hábitos pessoais e familiares. Apesar de levarem dessa vivência uma série de conhecimentos e experiências, carregam ainda muitas dúvidas e receios quanto às suas competências para lidar com a situação.

Mesmo com os avanços tecnológicos da Medicina, nem sempre o sistema de saúde é capaz de devolver às famílias de origem uma criança ou adolescente saudável. Em muitos casos, esse filho pode trazer consigo um prognóstico sombrio, marcado por inca- 
pacidades as mais diversas, perdendo de vista habilidades que caracterizam a noção de infância que todos nós temos: com o direito a correr, brincar e crescer. Assim, o grau de dependência de cuidados e de apoio biopsicossocial pode ser tão variável quanto são os diagnósticos e a diversidade dos quadros que se apresentam atualmente nos contextos da atenção em saúde.

Diante do exposto, foi estabelecido como objetivo geral do estudo: Compreender a experiência de assistência domiciliar prestada pela mãe de criança com doença crônica e dependente de cuidados complexos. A partir desse objetivo maior, foram estabelecidos três objetivos específicos: - apreender as dificuldades da mãe de criança com doença crônica, ao realizar cuidados complexos em ambiente domiciliar; - relacionar alternativas de enfrentamento utilizadas pelas mães cuidadoras na assistência domiciliar às crianças; e levantar os sentimentos e percepções de ser mãe/ cuidadora ante a execução de cuidados complexos.

\section{ABORDAGEM METODOLÓGICA}

Trata-se de um estudo de caráter qualitativo-descritivo desenvolvido com mães de crianças portadoras de problemas crônicos de saúde. Foram informantes do estudo seis mães residentes em três localidades da região norte e noroeste do estado do Paraná, mais especificamente nas cidades de Londrina, Maringá e Paranavaí, selecionadas a partir de contato dos autores em seus locais de trabalho. Os critérios de inclusão foram: ser mãe e cuidadora principal de criança com doença crônica dependente de cuidados complexos, que houvesse passado pela experiência de hospitalização nos últimos seis meses.

Os dados foram coletados no período de janeiro a março 2005 por meio de entrevistas, as quais foram previamente agendadas e realizadas no domicílio das mães. As respostas foram registradas integralmente no momento da entrevista e, como forma de validação, as respostas foram lidas no final para que as mães pudessem concordar com o seu conteúdo, completá-lo ou corrigi-lo.

0 instrumento utilizado na coleta de dados foi elaborado pelas próprias autoras com base nos objetivos do estudo. Trata-se de um roteiro de entrevista do tipo misto, constituído de 29 questões, abordando, além da caracterização da amostra, a vivência durante a hospitalização e a experiência com os serviços de saúde e com a realização dos cuidados com a criança.

Para a análise e interpretação dos dados, optou-se pela abordagem metodológica do Discurso do Sujeito Coletivo (DSC). Nessa abordagem, os depoimentos não se anulam ou se reduzem a uma categoria comum unificadora, já que o que se busca fazer é reconstruir, com pedaços de discursos individuais, como em um quebra-cabeça, tantos discursos-síntese quantos se julgue necessários para expressar um dado pensar ou representação social sobre um fenômeno(13).

O DSC, portanto, é uma reunião, agregação de pedaços isolados de depoimentos, de modo a formar um todo discursivo coerente, em que cada uma das partes se reconheça como constituinte desse todo e 0 todo constituído por essas partes. Quando se trata de discursos sensivelmente diferentes, a apresentação deles, em separado, é obrigatória, mas, se são complementares, podem ou não se apresentar em separado, na dependência de o pesquisador querer resultados mais detalhados ou mais genéricos ${ }^{(13)}$.

O DSC como técnica de processamento de dados com vistas à obtenção do pensamento coletivo dá como resultado um painel de discursos de sujeitos coletivos, enunciados na primeira pessoa do singular, justamente para sugerir uma pessoa coletiva falando como se fosse um sujeito individual de discurso(13).

A apresentação nesse formato procura garantir, entre outros aspectos, a preservação das identidades dos sujeitos investigados, cuja participação atendem as prerrogativas da Res. 196/96-CNS, acerca de pesquisas envolvendo seres humanos, destacando-se que o projeto foi aprovado pelo comitê de ética em pesquisa da Universidade Estadual de Maringá (Parecer 347/2004).

\section{CONHECENDO AS MÃES CUIDADORAS E SUAS VIVÊNCIAS}

As características do sujeito coletivo deste estudo encontram-se distribuídas no quadro 1 , donde se observa que as mães são relativamente jovens, têm um bom grau de instrução, e a maioria conta com a presença do pai da criança como possível colaborador na realização dos cuidados complexos com o filho. As famílias, todas com baixo poder aquisitivo, são do tipo nuclear e constituídas de 3 a 7 pessoas. 
Q uadro 01: Características das mães e crianças que constituem o sujeito coletivo de estudo. Maringá, 2005.

\begin{tabular}{|c|c|c|c|c|c|c|c|c|}
\hline Criança & Idade & $\begin{array}{c}\text { Diagnóstico } \\
\text { inicial }\end{array}$ & $\begin{array}{c}\text { Diagnóstico } \\
\text { atual }\end{array}$ & $\begin{array}{l}\text { Idade } \\
\text { da mãe }\end{array}$ & Escolaridade & $\begin{array}{l}\text { Renda } \\
\text { familiar } \\
(S M)\end{array}$ & $\begin{array}{c}\text { Estado } \\
\text { civil }\end{array}$ & $\begin{array}{l}\text { No de } \\
\text { filhos }\end{array}$ \\
\hline $\mathrm{Cl}$ & $1 \mathrm{a}$ & $\begin{array}{l}\text { Estenose de traquéia } \\
\text { e refluxo gastresofágico }\end{array}$ & $\begin{array}{l}\text { Traqueostomia } \\
\text { permanente }\end{array}$ & 25 & Ensino médio & 2 & Casada & 1 \\
\hline $\mathrm{C} 2$ & $5 a$ & $\begin{array}{c}\text { Malformação } \\
\text { congênita de rim, } \\
\text { bexiga, testículo e MSD }\end{array}$ & Colostomia definitiva & 32 & Ensino médio & 4 & Casada & 2 \\
\hline C3 & $6 \mathrm{~m}$ & $\begin{array}{l}\text { Hipóxia grave } \\
\text { pós-parada } \\
\text { cardiorrespiratória }\end{array}$ & $\begin{array}{l}\text { Atrofia cerebral, } \\
\text { broncopenumonia } \\
\text { e óbito }\end{array}$ & 28 & Ensino médio & $2 \frac{1}{2}$ & Casada & 1 \\
\hline C4 & $5 a$ & Estenose de traquéia & $\begin{array}{l}\text { Traqueostomia } \\
\text { por tempo indet. }\end{array}$ & 32 & $\begin{array}{l}\text { Esino } \\
\text { Fundamental }\end{array}$ & 1 & Casada & 5 \\
\hline C5 & $11 a$ & $\begin{array}{l}\text { Mega cólon congênito } \\
\text { crônico severo }\end{array}$ & $\begin{array}{l}\text { Obstrução intestinal } \\
\text { com colostomia }\end{array}$ & 28 & Ensino médio & $11 / 2$ & Solteira & 2 \\
\hline C6 & $13 a$ & Tumor no cerebelo & $\begin{array}{l}\text { Gastrostomia } \\
\text { há dois anos por } \\
\text { dificul//e deglutir }\end{array}$ & 31 & Ensino médio & 3 & Casada & 3 \\
\hline
\end{tabular}

No tangente à apresentação dos discursos do sujeito coletivo, na mesma perspectiva de Lefèvre, procuramos, a partir dos discursos individuais, construir categorias temáticas bastante amplas, que atendem o objetivo geral previamente determinado pela pesquisa, assim como subcategorias, resultantes da fluência desses discursos e oriundas das reflexões que emanaram deste processo interativo de entrevista.

Assim, por entender-se a construção desse discurso e dessa representação em "três níveis de consideração do problema, 0 descritivo, 0 interpretativo e o evolutivo"(14), a apresentação dos resultados do processo de análise dos discursos se dá por meio de três categorias temáticas mais amplas, a saber: "As dificuldades da mãe de criança com doença crônica ao realizar cuidados complexos"; "Enfrentamentos e desafios para a consolidação do cuidado domiciliar" e "Os sentimentos e percepções de ser mãe/cuidadora ante a execução de cuidados complexos". Tais categorias, por sua vez, abarcam subcategorias que representam ressonâncias das temáticas maiores, originadas do processo de interpretaçã̃o e evoluçãao dos discursos, como contribuições para a discussão e reflexão sobre o tema tratado.

As dificuldades da mãe de criança com doença crônica ao realizar cuidados complexos

A análise dos relatos das mães possibilitou verificar a correlação direta entre os sentimentos vivenciados e as dificuldades encontradas pelo grupo para interagir com seus filhos e lidar com sua condição. Para elas, o cuidado é concebido como algo solitário e centralizado na figura materna. 0 auxilio, quando existe, provém principalmente do marido ou companheiro e, em alguns casos, de outros membros da família, tais como outros filhos, avós ou tias.

$\mathrm{Na}$ unidade de terapia intensiva pediátrica, durante o processo de hospitalização, a mãe se revela como o elemento familiar que mais deseja e procura permanecer junto ao filho. A opinião dos maridos ou companheiros reiteram tal decisão ou conduta, na medida em que os mesmos consideram que "as crianças ficam melhor com as mães". Tal concepção reforça 0 ideário materno, historicamente construído, do papel da mãe como sustentáculo do lar e responsável principal pelo cuidado e educação da prole ${ }^{(13)}$.

Identifica-se também, de forma importante, 0 sentimento de medo, tanto em decorrência do não saber fazer (realizar) o cuidado, como também o receio em prestar este cuidado percebido como difícil. "Ser mãe", nesses casos, envolve uma postura de abnegação, uma necessidade de dedicação plena e constante durante as 24 horas do dia, deixando para segundo plano a preocupação com relação a si mesma, e ao sofrimento experimentado por essas mães em função de sua relação com a criança.

Não pensava em mim. 0 difícil era ver 0 sofrimento da criança. 
No tangente ao período de permanência da criança no ambiente hospitalar, as dificuldades relatadas dizem respeito, primeiramente, ao sofrimento da mãe em presenciar e compartilhar o sofrimento do filho, pontuado principalmente pelos procedimentos dolorosos e invasivos impostos pelo tratamento, bem como pelo tempo de espera até a definição do processo terapêutico a ser adotado, gerando ansiedade e medo(15).

Era difícil esperar o tempo para decidir o tratamento... 0 tempo de tratamento com antibiótico era muito longo, demorava para fazer tratamento. Pegar veia para pôr os medicamento era cada vez mais difícil...

Tais dificuldades se agigantam, com a constatação da necessidade de aprender e realizar procedimentos ou técnicas como a aspiração de vias aéreas, a alimentação por sonda nasogástrica ou gastrostomia. Acrescenta-se a isso toda a sensação de impotência ou despreparo para a execução de manobras tão específicas como as que constituem a realidade assistencial dessas crianças. 0 medo de não conseguir realizar um procedimento e o receio do que poderia acontecer durante a realização do mesmo constitui um sentimento muito presente entre as mães:

Quando ela estava internada, tinha medo que morresse afogada com tanta secreção, as auxiliares de enfermagem pediam que eu limpasse a traqueostomia com uma gaze, mas eu não tinha coragem, tinha medo da traqueostomia sair...

Sentia muita dificuldade em alimentar a criança, no início da gastrostomia....

São vários os sentimentos das mães cuidadoras ao enfrentar a doença de um filho. A angústia se revela tanto no momento do diagnóstico, nem sempre apoiado de forma adequada, como também ao longo dos dias de incerteza que se seguem, marcados especialmente por um processo de assimilação penosa de uma nova perspectiva de vida ${ }^{(17) .} 0$ nascimento de criança portadora de anormalidades é um problema que é carregado de culpa atribuída social e culturalmente à família, principalmente à mãe, gerando crise e negação das expectativas, sendo necessário à adaptação do filho idealizado para o real, processo este desenvolvido de forma lenta e conflituosa, e que pode ser vivenciada como um golpe ${ }^{(13,16)}$.
Quando a criança nasceu, não me mostraram, depois o médico foi conversar e falou que o caso era sério. Sentia muita ansiedade para terminar tudo e ir para casa..

Senti dificuldade, porque não conhecia, foi difícil aceitar. Difícil de como cuidar, eram 2 crianças prematuras. Era muita coisa para uma criança só. Sabia que a vida ia mudar muito...

Tinha muitas dúvidas e muito medo, pois tinha $4 \mathrm{ff}$ Ihas normais e aquela era diferente, tinha medo que ela não fosse falar, não ser normal como as outras crianças, ninguém dava as informações de que eu necessitava, os médicos e enfermeiros não garantiram que a criança iria falar.

Tal sensação é agravada pela ameaça sombria e sempre presente da perda da criança, pela sensação de despreparo e pela busca constante de definições.

Não gostava do ambiente, não tinha previsão de alta e isso gerava angústia. .... Ficava triste, insegura, me sentia despreparada.Eu ficava bem, quando minha filha estava bem. E muito mal quando ocorria a piora dela...

0 sofrimento compartilhado com seus filhos e a pequena inserção no processo de assistência durante a internação, acarreta os sentimentos de insegurança, dúvidas, esmorecimento, dor e aflição, que, por conseguinte propicia a dificuldade na execução e efetivação dos cuidados com a criança. Alguns autores afirmam que as situações de doenças despertam nos cuidadores e em toda a família o medo da morte, e 0 sentimento de perda. ${ }^{(8,15,18)}$.

Durante o tempo de internação na UTI pediátrica recebi poucas orientações a respeito dos cuidados mais complexos, quando foi para a enfermaria da pediatria, ela foi recepcionada pela auxiliar de enfermagem... recebi poucas informações e também fui pouco inserida nos cuidados devido à insegurança e ao medo. No penúltimo dia antes da alta hospitalar, eu fiz uma lista das principais dúvidas com relação aos cuidados, que foi respondida por escrito pela enfermeira da unidade...

As mães do estudo encontravam-se nessa rotina de cuidados durante períodos que variavam de 0 a 6 anos, marcados eminentemente pela dedicação ex- 
clusiva aos seus filhos doentes. Apenas uma das mães cuidou de seu filho por um pequeno período - cerca de 10 dias, em função do óbito da criança. Outros estudos ${ }^{(8,13)}$ também constataram que a mãe é quem assume sozinha a rotina dos retornos ambulatoriais, internações, cuidados, horário dos remédios e intercorrências.

Com todo 0 arsenal tecnológico atualmente disponível e utilizado na área de saúde, a tendência parece ser a de que cada vez mais crianças sejam salvas, alargando a margem de sobrevivência de pacientes outrora condenados.

Dados americanos apontam que as crianças com necessidades especiais, são estimadas em 10 a $15 \%$ da população daquele país com menos de 21 anos de idade. $E$ desta população, $90 \%$ estão alcançando a vida adulta, estas crianças apresentam necessidades de saúde tão complexas que o próprio sistema se sente inapropriado para atendê-las ${ }^{(10: 8)}$.

Sendo a permanência no hospital algo menos desejável, visto a ênfase crescente dada às iniciativas que privilegiam o cuidado domiciliar e a inserção dos indivíduos em seu seio familiar e meio social, há que se questionar se as instituições hospitalares encontram-se de fato preparadas para possibilitar tais mudanças, com impactos reais sobre a conjuntura da atenção à saúde dos diversos segmentos da sociedade.

\section{Enfrentamentos e desafios para a consolidação do cuidado domiciliar}

A notícia da alta hospitalar é, em geral, algo pelo qual a criança e família anseiam mais do que tudo. No entanto, no contexto da cronicidade, a alta suscita uma série de outras preocupações. Uma das mães referiu ter sentido muito o medo quando saiu de alta pela primeira vez e por esta razão foi buscar 0 auxilio da família. Somente uma das mães relatou ter ficado feliz, porém preocupada, e uma outra mãe referiu que ela solicitou a alta, pois a criança estava muito agitada e acreditava que em casa, com a companhia dos irmãos, poderia ficar mais calma e isto influenciar positivamente em sua recuperação.

Assim, entre as mães participantes do estudo, a notícia da alta aparecia novamente vinculada ao sentimento de medo e angústia:

...foi difícil.Tinha medo de não dar conta, ficava em cima da criança. Medo de que acontecesse algu- ma coisa, se acontecesse me sentiria responsável.Quando ele saiu de alta pela primeira vez fui para a casa da minha mãe e a segunda vez fui para a minha casa. Sai feliz, acredito que já tinha muita informação, perguntava tudo, todas as dúvidas. Tinha medo quando ele ficava roxo. Colocava oxigênio mas tinha medo de não resolver.

Me sentia muito incapaz, não achei que daria conta. Não achei que iria sobreviver. Não achei que teria tanta força. Depois fui me adaptando, todo mundo se adapta.

Neste momento tive a sensação que o mundo estava desabando em cima da minha cabeça, senti muito medo de que a criança pudesse morrer em casa por falta de assistência...

Senti muito medo em ir para casa, pois não possuía as condições necessárias para cuidar do bebê no domicílio, medo que ela passasse mal e morresse sem que pudesse fazer alguma coisa..

Feliz, porém preocupada com o que me esperava para dar continuidade no tratamento, sabia que precisava retornar sempre ao hospital. Até quando, e como seria a vida daqui pra frente..

Embora tais sentimentos sejam uma constante na vida dessas mães, dentro do ambiente hospitalar as mesmas pareciam viver a sensação de partiIha da responsabilidade sobre a criança, respaldadas, até certo ponto, pela equipe de saúde e pelo arsenal tecnológico existente naquele ambiente tantas vezes tido como frio, asséptico e hostil. De volta a seus lares, no entanto, as mães se percebiam na condição de terem de lidar e enfrentar qualquer situação de forma isolada, solitária e independente. Nesse contexto, as participantes se vêem compelidas a buscar o apoio necessário junto às suas famílias, e vivem a ambigüidade de sentimentos: o contentamento pela alta, em contraposição à ansiedade e receio do que pode ocorrer fora do ambiente hospitalar.

\section{Sobre as orientações e o preparo para a alta}

Todas as mães relataram ter recebido orientações por ocasião da alta, porém o nível de complexidade de 
muitos procedimentos dificultava, a princípio, a compreensão das informações. Na maioria dos serviços e mesmo entre os profissionais de saúde, não existe uma preocupação ou consciência sobre as diferenças na capacidade das mães para assimilação das orientações, de forma que, durante a hospitalização da criança, os profissionais costumam delegar à mãe atividades simples e às vezes atividades complexas, sem orientação e supervisão necessárias ${ }^{(9)}$. Assim, embora façam parte do cotidiano hospitalar, bem como compõem o repertório de habilidades dos profissionais, todo e qualquer tipo de procedimento representa algo muito novo e abstrato para a população leiga, da qual provém a grande parte dos usuários do sistema de saúde.

É necessário, portanto, que consideremos a necessidade do estabelecimento de uma relação de empatia, com abertura por parte dos serviços e de seus profissionais, no sentido de buscar perceber e receber de forma compreensiva as possíveis dificuldades da clientela, trabalhando-as de modo paciente e sensivel. Há que se investir num processo de ensinoaprendizagem sistematizado, buscando trabalhar desde as noções mais básicas do cuidado, como a identificação e a manipulação de materiais, até a execução das diversas etapas que compõem uma técnica, com a observância dos cuidados de anti-sepsia, bem como 0 conforto e o bem-estar do paciente.

Da mesma forma, a indisponibilidade eventual de equipamentos e materiais deve ser prevista pela equipe, e a orientação dirigida no sentido de improvisar algumas alterações que viabilizem a execução dos cuidados. Algumas impressões e vivências das mães por ocasião da alta de seus filhos são apresentadas abaixo:

0 residente me passou uma lista dos equipamentos e materiais que deveria ter em casa. A enfermeira devolveu a lista com minhas dúvidas, respondida por escrito e outras mães que estavam com seus filhos internados e que enfrentaram situações parecidas, explicaram como cuidavam de seus filhos em casa...

Precisava aprender sobre a aspiração, e a manipular a sonda e dar a medicação. As dúvidas foram sendo solucionadas durante o período de internação.

Como cuidar da colostomia. Como fazer curativo na sonda. Lavar as mãos, banho. No início ia alguém para me ajudar e depois fui fazendo só...
Fui orientada a aspirar a traqueostomia com seringa, sonda e solução fisiológica. Tive noções sobre infecção, porém, não tinha luva para aspirar, então, lavava a mão e passava álcool.

Muito embora todas as mães relatem ter recebido orientações sobre a execução das técnicas e/ou procedimentos a serem realizados no domicílio, como mostram os relatos acima, em sua maioria, as participantes consideraram esse preparo insuficiente. Assim, ao chegarem em casa, muitas acreditam não conseguir desenvolver de forma satisfatória o cuidado ensinado. Ao serem questionadas quanto à capacidade adquirida para executar o que thes havia sido informado ou orientado, as mães referiram:

Não..., fui para a casa com muitas dúvidas, algumas foram sanadas pela equipe do PSF e outras tantas fui descobrindo sozinha, em casa, no dia-a-dia.

Não..., eu acabava tendo de levar o bebê todos os dias para o hospital, às 6:00hs da manhã, e voltava para casa lá pela meia-noite

Contudo, nos casos em que as respostas tiveram caráter positivo, foi possível evidenciar o nível de interesse das mães em buscar a construção de competências para este fim, ou a utilização de mecanismos próprios para vencer as dificuldades:

Fui esclarecida. Quando tinha dúvidas perguntava tudo. ... de tanto fazer quando estava internado. ... além da prática, as orientações vieram escritas e quando tenho dúvidas procuro o dicionário...

Entre os recursos necessários à consolidação dos cuidados domiciliares, por meio de uma rede de apoio e suporte às famílias, é importante destacar o papel dos serviços de saúde ambulatorial, representada pelas Unidades Básicas de Saúde, e em especial pelas equipes de saúde da família (Programa de Saúde da Família). Apenas uma das mães referiu não dispor de qualquer serviço de apoio ou suporte na região em que residia. Esse fato é revelador da importância da rede de integração da assistência no SUS (Sistema Único de Saúde), bem como de buscar meios para a consolidação de um sistema de referência e contrareferência realmente efetivo.

A existência de dificuldades na realização dos cuidados foi apontada por todas as mães, dificuldades estas em geral relacionadas à execução dos procedimentos de caráter complexo: 
...aspiração, pois tinha medo de traumatizar a traquéia..., que a cânula saísse..

Passar sonda nasogástrica, pois tinha medo de sangrar. De.passar a dieta e obstruir a sonda..

0 medo e a insegurança observados nos relatos são decorrentes, não raramente, de orientações insuficientes, ou efetuadas de forma ineficiente durante o período de hospitalização das crianças. Nós, como cuidadores formais ou profissionais, ao atuarmos junto às mães/ cuidadoras, usualmente apresentamos uma tendência de agir como se elas tivessem bagagem teórica e prática capaz de respaldar o desenvolvimento eficiente de uma série de procedimentos complexos. Não raramente, nos esquecemos de que, para chegarmos à nossa condição atual, de considerarmos demasiadamente simples e rotineiros tal tipo de cuidados ou procedimento, passamos anos nos bancos das escolas e universidades.

Assim, buscar em nosso passado e em nossas próprias vivências os sentimentos de insegurança experimentados ao longo de nossos primeiros anos de formação e de atuação profissional nos possibilitaria uma aproximação com relação à sensação experimentada pelas mães cuidadoras expostas a tais exigências e desafios, tornando-nos, desse modo, mais capazes de compreender 0 universo de necessidades a serem trabalhadas na busca da minimização do medo e consolidação da aprendizagem efetiva do cuidar. Sendo assim, devemos utilizar como instrumento a prática da supervisão, da orientação e da educação continuada para inserir a mãe nesse processo de transformação do cuidado ${ }^{(10)}$

Os sentimentos e percepções

de ser mãe/ cuidadora ante

a execução de cuidados complexos

- Sobre o que muda na vida do ser cuidador e do ser cuidado na vivência da cronicidade

Não é difícil supor a transformação que se instala na vida de pessoas obrigadas a enfrentar uma situação como a da doença crônica na infância. As mães referiram alterações muito significativas em suas vidas, em todos os sentidos. Tais mudanças se refletem no mundo do trabalho, que muitas são obrigadas a deixar, juntamente com os anseios e sonhos individuais. Também são afetadas em seus papéis de esposas, amigas e mulheres, deixando de lado sua sexualidade, seu lazer, sua vida ${ }^{(8,13,18)}$, em função da canali- zação de todas as energias e esforços em direção a um objetivo único que é cuidar do filho doente.

...mais responsabilidade, agora dobrou. Mudei de cidade. 0 marido deixou o emprego. Não achava que era tão complicado,a gente esquece da gente, perde a graça, fica muito preocupada com qualquer coisa... Saí do trabalho. Quando vamos para algum lugar tem que levar muita coisa, ou quase tudo. ... aprendi a ser paciente.

Tudo, dedicação exclusiva 24 horas... Parei a minha vida, parei de trabalhar, isolei-me dos amigos, da família e a vida conjugal ficou muito difíicil, pois às brigas tornaram-se muito freqüentes... Não consegui cuidar das outras crianças direito, o marido ficava bravo porque tinha que cuidar das crianças, fazer comida e trabalhar na roça sozinho. As filhas cobravam mais atenção...

A sobrecarga que recai sobre os ombros da mãe, como principal cuidadora da criança portadora de um problema crônico de saúde, freqüentemente faz com que a mesma passe a desenvolver estratégias para lidar com os novos contextos e as novas exigências que a vida the impõe, o que, por sua vez, representa um estímulo para que as mesmas se sintam mais capazes e sempre abertas para a aprendizagem.

Nesse processo de apoio e suporte ao cuidador familiar, torna-se imprescindível o desenvolvimento de uma infra-estrutura familiar favorável, a fim de evitar 0 desgaste natural, provocado pelo cansaço e pelo estresse associados a este encargo. Na medida em que há "familiares dispostos a dividir esta responsabilidade no cuidado... pode haver menos desgaste físico e mental para todos, com repercussões na qualidade de vida dos envolvidos no cuidado domiciliar", (19)

Sobre o que poderia ser feito para melhorar a assistência e o preparo para o cuidado domiciliar: ouvindo a voz do cuidador familiar

Ao serem solicitadas a emitir sugestões no sentido da melhoria do atendimento nos serviços de saúde, a grande maioria das participantes enfocou 0 aspecto psicológico e a necessidade de humanização da assistência, como pontos nevrálgicos e merecedores de uma abordagem mais incisiva. Tais aspectos que, infelizmente, parecem esquecidos ou negligenciados em muitas realidades, por parte dos profissionais envolvidos no cuidado, em função do enfoque tecnicista e eminentemen- 
te organicista das atividades profissionais, não deixam, no entanto, de serem lembrados e classificados como sendo essenciais por parte da clientela.

A capacitação dos profissionais para a interação terapêutica remete à necessidade de trabalhar habilidades também educativas, de modo a dotar a equipe de saúde de um arsenal de competências que the permitam compreender e agir de forma mais eficiente na construção de uma interação efetiva, bem como na consolidação de uma aprendizagem significativa para 0 cuidado domiciliar e a redução dos níveis de dependência por parte da clientela de mães e crianças atendidas.

Os profissionais de saúde estão pouco preparados para cuidar e ensinar a cuidar de crianças complexas. Precisaria haver melhor treinamento para os residentes, internos, auxiliares de enfermagem e alguns enfermeiros, para que eles pudessem trabalhar de forma mais humana com os pais das crianças internadas, dando à eles um suporte emocional. No hospital devia ter mais tratamento psicológico. Eles deveriam cuidar melhor das pessoas, serem mais educados e seria bom se fornecessem mais materiais.

- Sobre o significado de ser mãe e cuidadora de uma criança com doença crônica

Ao se manifestarem sobre o significado de ser mãe de uma criança crônica, verifica-se que os relatos das participantes voltam-se novamente para a questão da dedicação total ao filho. Das habilidades e mecanismos desenvolvidos para enfrentar todas as situações impostas pela condição dos filhos, são apontados: a paciência, a coragem e a força interior para superar as incertezas quanto ao futuro. Quase todas as mães evidenciam experiências vividas como um grande aprendizado pessoal, relatando como conseqüência direta dessa vivência o fortalecimento e o crescimento pessoal, enquanto seres humanos e mães.

Somente uma mãe se referiu à experiência como uma cruz bastante pesada, que a levou por vezes a pensar em desistir, frente aos momentos de incerteza e à falta de respostas ou perspectivas quanto à condição e duração de vida da criança. Sentimentos pesados como este, caracterizam o ônus de um contexto socioeconômico precário, marcado por reinternações freqüentes e dolorosas, e por um diagnóstico crônico severo ${ }^{(6,20-21)}$.

Os relatos mostram-se impregnados de experiências e sensações: tempestades de incerteza e de dú- vidas, caracterizados pelo medo do desconhecido na fase inicial, passando pelo receio da morte presente ao longo de quase toda a trajetória, e o sentimento de vitória e fortalecimento ao suplantarem os tantos obstáculos apresentados nesse caminho tortuoso.

Assim, levadas a uma reflexão acerca de tudo o que deixaram para trás, as participantes conseguem reconhecer a capacidade adquirida de aprender, de questionar e de também executar atividades nunca antes imaginadas...0 que, em última análise, constitui uma vivência ímpar e especial, como também são seus filhos.

Em alguns relatos percebe-se também um sentimento de cumplicidade entre mãe e filho - cumplicidade construída por meio do sofrimento compartilhado, e pela superação diária dos limites físicos e psíquicos. Desse modo, cada etapa vencida ou superada, cada pequena aquisição do filho, cada aprendizado, cada momento único, se traduz em elemento consolidador dos laços afetivos desse binômio, e em vitória capaz de alavancar um próximo passo.

Tem que se dedicar totalmente, 24 horas por dia. Ele dorme comigo. Nós nos entendemos bem... É muito especial, muito abençoado. A criança vai ensinando muita coisa. As pessoas vêem você como uma pessoa especial. 0 meu filho acompanhava tudo, ele não tem vergonha de nada. A criança deve aprender a viver e conviver com os outros. Não tratar de forma diferente. Sempre tratei as duas crianças de forma igual...

Para mim foi uma grande experiência, levarei para sempre dentro de mim, isso me ajudará quando eu tiver outro filho, pois minha atenção será redobrada. Apesar das dificuldades e dos sofrimentos, iremos procurar passar para outros casais a nossa experiência. Os profissionais de saúde estão pouco preparados para cuidar e para ensinar à cuidar de crianças complexas...

Mudou muita a vida. A necessidade fez correr atrás, perguntar, tirar as duvidas...Hoje não tenho medo de enfrentar situações difíceis, acho tudo mais fácil e só não sou mais feliz porque falta muita coisa em minha casa...

É uma cruz bastante pesada, às vezes penso em desistir, o que me deixa mais triste é que os médicos não sabem o que vai acontecer. Como vai ser a vida dela? Até quando? ... 
Difícil aceitar a situação, requer muita dedicação principalmente paciência até no envolvimento com a família, na dificuldade de se comunicar. Mas me sinto vitoriosa pelo fato de não depender totalmente dos outros e espero um dia a minha criança volte a se alimentar normalmente...Vitória, do jeito que ele nasceu e como esta...

\section{CONSIDERAÇÕES FINAIS}

Buscar nas singularidades e nas vivências de uma clientela específica os subsídios para o delineamento de suas reais necessidades permite-nos incrementar as possibilidades de trabalhar mais efetivamente em prol dessas pessoas.

Assim, identificar o ser mãe cuidadora da criança crônica, desvelando seus sentimentos e opiniões, caracterizando suas dificuldades e os processos utilizados pelas mesmas para o enfrentamento das situações no cotidiano permitem um diagnóstico mais preciso do contexto assistencial.

0 presente estudo possibilitou-nos, assim, evidenciar que o cuidado com a criança complexa implica necessariamente considerar este tipo de paciente na perspectiva de sua vinculação com a figura da mãe ou cuidadora, em que o bem-estar de um afeta diretamente a condição do outro, e onde o bem assistir a criança perpassa a orientação e 0 envolvimento pleno da mãe no processo.

Para repensar o sistema de saúde e a assistência mais plena a clientelas especiais, torna-se imprescindível uma postura de análise crítica acerca de nossas deficiências atuais. Os relatos dessas mães nos levam a concluir que se, por um lado, a tecnologia e o desenvolvimento técnico-científico propiciaram condições para 0 alargamento das possibilidades de sobrevida desses cidadãos, por outro lado, nossas competências não avançam muito para além do tecnicismo, deixando um abismo a ser preenchido com habilidades educativo-pedagógicas e relacionais que dêem conta de um fazer profissional mais completo e adequado.

0 momento da alta dessas crianças é singular na vida do paciente e de sua cuidadora. No entanto, em boa parte dos serviços de saúde, essa mesma mãe é pouco ouvida e compreendida em suas dificuldades, 0 que implica a necessidade de revermos nossas práticas assistenciais e educativas de modo a identificar os principais obstáculos para o ensino e a aprendizagem do processo de cuidar da criança.

Cabe a todos os profissionais envolvidos e de forma particular ao enfermeiro, traçar metas para que tanto a criança / adolescente quanto sua família sejam acompanhados e assistidos adequadamente e com vistas a capacitar a mãe/cuidadora a incluir em sua rotina de cuidados á criança no domicílio, o desenvolvimento de cuidados complexos.

Nessa perspectiva, durante o período de internação hospitalar, muito antes da programação de alta hospitalar, a mãe já deve ser inserida no cuidado junto à criança e ao adolescente cronicamente enfermo. 0 trabalho de inserção da mãe/cuidadora, no cuidado no entanto, deve iniciar-se de forma lenta e gradativa e ir progredindo em conformidade ao seu processo de aprendizagem e na medida em que suas dúvidas vão sendo sanadas. Assim, os cuidados aprendidos durante a internação hospitalar poderão ser executados por essas cuidadoras em casa. Desse modo, as mães tornam-se aptas à realização desse cuidado de forma prática e eficiente, 0 que pode ser um fator determinante na prevenção das reinternações freqüentes dessas crianças e adolescentes, fato este que redunda tanto em prejuízos emocionais quanto financeiros.

Muito embora, no contexto da equipe de saúde, 0 enfermeiro se caracterize como o profissional mais apto a inserir a mãe no processo de cuidado direto junto ao filho doente, bem como na prevenção de danos e na busca pela recuperação da qualidade de vida, nem sempre este profissional está suficientemente preparado para lidar com as expectativas, as ansiedades e 0 medo presentes neste processo de aprendizagem tão específico. Assim, além da capacitação teórica e técnico-científica para proceder à inserção efetiva da mãe no processo de construção gradativa desta auto-suficiência, é primordial, para o profissional enfermeiro, a capacidade de reconhecimento dessas variáveis que determinarão o sucesso ou o fracasso da empreitada.

Estar apto a exercer esse papel mediador, como educadores e agentes de transformação social, tanto no âmbito da assistência curativa quanto no da promoção à saúde e prevenção de complicações, representa uma faceta da humanização da assistência a ser resgatada, e um compromisso a ser assumido por profissionais e por formadores no intuito de alcançar a tão sonhada qualidade da atenção em saúde. 


\section{Referências}

1. Spinsanti S. A vida pré-natal e o nascimento, nova tarefa da humanização: o nascimento. In: Ética biomédica. São Paulo(SP): Paulinas; 1990. p. 55-67.

2. Engelhardt J, Tristam H. Fundamentos da bioética. Tradução de José A. Ceschin. São Paulo(SP): Loyola; 1998. p. 287-344.

3. Rocha SMM, Nascimento LC, Lima RAG. Enfermagem pediátrica e abordagem da família: subsídios para 0 ensino da graduação. Rev Latino-am Enfermagem 2002 out; 10(5): 709-14.

4. Lepargneur H. Que esforço é mister desempenhar para prematuros poucos viáveis? 0 Mundo da Saúde 1998; 22(6): 357-65

5. Fernandes AT. O desafio da infecção hospitalar: a tecnologia invade um sistema em desequilíbrio. In: Fernandes TA, Filho RN, Fernandes MOV. Infecções hospitalares e suas interfaces na área da Saúde. São Paulo(SP): Atheneu; 2000. p. 206 - 208.

6. Vieira MA, Lima RAG. Crianças e adolescentes com doença crônica: convivendo com mudanças. Rev Latino-am Enfermagem 2002; 10 (4): 552-60.

7. Lima RAG. A enfermagem na assistência à criança com câncer. Goiânia(GO): AB; 1995.

8. Costa JC. Crianças/adolescentes em quimioterapia ambulatorial: implicações para a enfermagem. Rev Latino-am Enfermagem 2002; $10(3): 321-33$.

9. Lima RAG, Rocha SMM, Scochi CGS. Assistência à criança hospitalizada: reflexões acerca da participação dos pais. Rev Latino-am Enfermagem 1999; 7(2): 33-9.

10. Madeira LM. Alta hospitalar da criança: implicações para a enfermagem. Rev Bras Cresc Desenv Hum 1994; 4(2): 5-11.

11. Vila VSC. 0 significado cultural do cuidado humanizado em Unidade de Terapia Intensiva: "Muito falado e pouco vivido". Rev Latino-am Enfermagem 2002; 10 (2): 137-44.

12. Ribeiro NRR. A família enfrentando a doença grave da criança. In: Elsen I, Marcon SS, Silva MRS. 0 viver em família e sua interface com a saúde e a doença. 2a ed. Maringá(PR): UEM; 2004. p. 183-198.

13. Furlan MFFM, Ferriani MGC, Gomes R. O cuidar de crianças portadoras de bexiga neurogênica: representações sociais das necessidades dessas crianças e suas mães. Rev Latino-am de Enfermagem 2003 nov/dez; 11(6): 763-70.

14. Lefèvre F, Lefèvre AMC. 0 discur so do sujeito coletivo: um enfoque em pesquisa qualitativa .Caxias do Sul (RS): EDUCS; 2003.

15. Furtado MCC, Lima RAG. 0 cotidiano da família com filhos portadores de fibrose cística: subsídios para a enfermagem pediátrica. Rev Latino-am Enfermagem 2003 jan/fev; 11(1): 66-73.

16. Fernandes MGO, Viana DL, Balbino FS, Hor ta AL. Entrevistando as famílias de recém nascidos mal-formados como proposta de avaliação e de intervenção de enfermagem. Rev Acta Scientiarum 2004 jan/ jun; 26(1): 159- 65
17. Martins DA, Polak INS. Cuidando do portador de síndrome de Down e seu significante. Ciência, cuidado e saúde 2002; 1(1): 117- 22.

18. Resta DG, Budó MLD. A cultura e as formas de cuidar em família na visão de pacientes e cuidadores domiciliares. Rev Acta Scientiarum 2004 jan/jun; 26(1): 53-60.

19. Paes PFA, Espírito Santo FH. Limites e possibilidades no cotidiano do familiar que cuida do idoso com Alzeheimer no ambiente domiciliar. Esc Anna Nery Rev Enferm 2005 ago; 9 (2): 192- 98.

20. Lunardi VL, Lunardi WDF, Silveira RS, Soares NV, Lipinski JM. 0 cuidado de si como condição para o cuidado dos outros na prática de saúde. Rev Latino-am Enfermagem 2004 nov/dez; 12 (6): 933-39.

21. Andraus LMS, Oliveira LMAC, Minamisava R, Munari DB, Borges IK. Ensinando e aprendendo: uma experiência com grupos de pais de crianças hospitalizadas. REE-Revista Eletrônica Enfermagem 2004 jan/abr; [citado dez 2004] 6 (1): 98-103. Disponível em: http:// www.fen.ufg.br .

\section{Sobre as Autoras}

\section{Maria Inez Almeida}

Universidade Estadual de Londrina

Rosemeire Cristina Moretto Molina

Universidade Parananense - Unipar

\section{Tereza Maria Mageroska Vieira}

Faculdade Estadual de Educação, Ciências e Letras de Paranavaí

leda Harumi Higarashi

Universidade Estadual de Maringá

\section{Sonia Silva Marcon}

Universidade Estadual de Maringá 